\title{
Investing in breastfeeding - the world breastfeeding costing initiative
}

\author{
Radha Holla-Bhar ${ }^{1 *}$, Alessandro lellamo², Arun Gupta ${ }^{1}$, Julie P Smith ${ }^{3,4}$ and Jai Prakash Dadhich ${ }^{4}$
}

\begin{abstract}
Background: Despite scientific evidence substantiating the importance of breastfeeding in child survival and development and its economic benefits, assessments show gaps in many countries' implementation of the 2003 WHO and UNICEF Global Strategy for Infant and Young Child Feeding (Global Strategy). Optimal breastfeeding is a particular example: initiation of breastfeeding within the first hour of birth, exclusive breastfeeding for the first six months; and continued breastfeeding for two years or more, together with safe, adequate, appropriate, responsive complementary feeding starting in the sixth month. While the understanding of "optimal" may vary among countries, there is a need for governments to facilitate an enabling environment for women to achieve optimal breastfeeding. Lack of financial resources for key programs is a major impediment, making economic perspectives important for implementation. Globally, while achieving optimal breastfeeding could prevent more than 800,000 under five deaths annually, in 2013, US\$58 billion was spent on commercial baby food including milk formula. Support for improved breastfeeding is inadequately prioritized by policy and practice internationally.

Methods: The World Breastfeeding Costing Initiative (WBCi) launched in 2013, attempts to determine the financial investment that is necessary to implement the Global Strategy, and to introduce a tool to estimate the costs for individual countries. The article presents detailed cost estimates for implementing the Global Strategy, and outlines the WBCi Financial Planning Tool. Estimates use demographic data from UNICEF's State of the World's Children 2013.

Results: The WBCi takes a programmatic approach to scaling up interventions, including policy and planning, health and nutrition care systems, community services and mother support, media promotion, maternity protection, WHO International Code of Marketing of Breastmilk Substitutes implementation, monitoring and research, for optimal breastfeeding practices. The financial cost of a program to implement the Global Strategy in 214 countries is estimated at US $\$ 17.5$ billion ( $\$ 130$ per live birth). The major recurring cost is maternity entitlements.
\end{abstract}

Conclusions: WBCi is a policy advocacy initiative to encourage integrated actions that enable breastfeeding. WBCi will help countries plan and prioritize actions and budget them accurately. International agencies and donors can also use the tool to calculate or track investments in breastfeeding.

Keywords: Breastfeeding, Costs and cost analysis, Breastfeeding investment, Child survival, Health plan implementation, Health promotion/Economics/*Organization \& administration, National health programs/ economics $/{ }^{*}$ Organization \& administration, Program development/Economics

\footnotetext{
* Correspondence: holla.radha@gmail.com

'International Baby Food Network (IBFAN) Asia, BP 33 Pitampura, New Delhi, India

Full list of author information is available at the end of the article
}

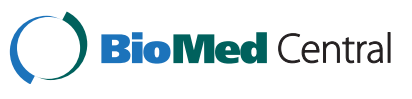

(c) 2015 Holla-Bhar et al.; licensee BioMed Central. This is an Open Access article distributed under the terms of the Creative Commons Attribution License (http://creativecommons.org/licenses/by/4.0), which permits unrestricted use, distribution, and reproduction in any medium, provided the original work is properly credited. The Creative Commons Public Domain Dedication waiver (http://creativecommons.org/publicdomain/zero/1.0/) applies to the data made available in this article, unless otherwise stated. 


\section{Background}

More than 800,000 under five deaths a year could be prevented globally by achieving optimal breastfeeding practices, as recommended by the World Health Organization (WHO) and UNICEF - initiation of breastfeeding within the first hour after the birth; exclusive breastfeeding for the first six months; and continued breastfeeding for two years or more, together with safe, nutritionally adequate, age appropriate, responsive complementary feeding starting in the sixth month [1].

Global optimal breastfeeding rates remain abysmally low regardless of overwhelming scientific evidence to support the importance of optimal breastfeeding practices for child mortality, morbidity and malnutrition, and non-communicable diseases in adult life [2-5]. Equally, over the past decade, growth in global sales of baby foods mainly milk formula accelerated from $\$ 22.4$ billion in 2003 to over $\$ 58$ billion in 2013 [6]. Nearly half this sales growth has been in the developing countries of the Asia Pacific region, with breastfeeding declining rapidly in populous low and middle income countries such as China and Indonesia.

Health agencies have identified evidence-based strategies for promoting optimal breastfeeding in the 2003 WHO/UNICEF Global Strategy for Infant and Young Child Feeding (Global Strategy) [1]. The absence of economic perspectives has been cited as a barrier to the practical implementation of the Global Strategy [7], economic and financial factors are crucial to its justification and success. Markets fail to provide incentives for the achievement of optimal breastfeeding [8] and do not adequately promote and protect the associated potential for large international economic gains [9]. These economic and financial benefits for health systems in developed and developing countries have been demonstrated at both macro and microeconomic level [10-15]. Breastfeeding is one of the most cost effective 'interventions' to prevent under -five mortality [16]. Of available interventions, counselling about breastfeeding (and fortification) is said to have the greatest potential to reduce the burden of child mortality and morbidity [17]; breastfeeding programs cost from $\$ 100$ to $\$ 200$ per death averted, making them equally or more costeffective than measles and rotavirus vaccination [18].

The World Breastfeeding Trends Initiative (WBTi) was established in 2004 to contribute to the monitoring and effective implementation of the Global Strategy with indicators to address its key policies and programs (Table 1) [19], The WBTi database currently includes 54 of the 75 Millennium Development Goal 'countdown' countries (where more than 95\% of maternal, newborn, and child deaths occur). A recent study has used WBTi data on policy performance to show an association between aggregate scores and changes in exclusive breastfeeding (EBF) rates for 22 countries, suggesting that
Table 1 World Breastfeeding Trends Initiative (WBTi) policy and process implementation indicators

\begin{tabular}{l} 
Indicators \\
\hline 1. National policy, program and coordination \\
2. Baby friendly hospital initiative (BFHI) \\
(Ten steps to successful breastfeeding) \\
3. Implementation of the WHO International \\
$\quad$ code of marketing of breastmilk substitutes \\
(International code) \\
4. Maternity protection \\
5. Health and nutrition care system (in support \\
6. Maternal support and community outreach/community-based \\
7. Information support \\
8. Infant feeding and HIV \\
9. Infant feeding during emergencies \\
10. Mechanisms of monitoring and evaluation systems \\
\hline
\end{tabular}

implementing Global Strategy policies and programs can increase EBF [19].

Gupta et al. reviewed the evidence and recommended that seven strategic actions need to be taken by countries to ensure good implementation of the Global Strategy [20]. A 2013 UNICEF report has identified, lack of political will and low financial investments for breastfeeding are contributing to the lack of progress in optimal Infant and Young Child Feeding (IYCF) [21]. For example, a recent report on the global status of breastfeeding policies and programs in 40 countries, using the WBTi database, showed that no country assessed has fully implemented the Global Strategy [22].

Creating an enabling environment for optimal breastfeeding requires full implementation of the Global Strategy including provision of unbiased correct information, protection from commercial pressures and misinformation through effective implementation of the WHO International Code of Marketing of Breastmilk Substitutes (henceforth the International Code) [23] and national legislation. Also important are the facilitation of establishment and referral to an effective support structure that includes one-to-one and group counselling, and adequate maternity leave protection to every woman, all of which need to be scaled up to $100 \%$. While facilitating optimal breastfeeding requires financial outlay the health costs of premature weaning are increasingly evident [24-26], there is no corresponding investment to support women to this end and breastfeeding remains amongst the most underfunded nutrition interventions [27].

The World Bank's Scaling Up Nutrition estimates [28] are widely used as a reference for costing including on nutrition interventions such as fortification or supplementation. These estimates of financial resources needed for scaled up implementation of maternal and child nutrition 
initiatives are a good start, but have insufficient detail to support a policy focus on breastfeeding. The estimates address just one component of the environment needed for making breastfeeding more universal - the promotion of behavioural change via counselling. Consideration of broader economic aspects could further the implementation of the policies and interventions in the Global Strategy [7].

The WBC $i$ was launched in 2013 by International Baby Food Action Network (IBFAN) Asia and Breastfeeding Promotion Network of India (BPNI) to redress deficits in financial information needed to support implementation of the Global Strategy. The WBCi consists of an advocacy document, The Need to Invest in Babies, and a financial planning tool. While "The Need to Invest in Babies" provides estimates [29], the financial tool provides for 'handson' budgeting.

While the understanding of "optimal" breastfeeding may vary among, and within countries, there is a need to encourage governments to facilitate an enabling environment for women to achieve optimal breastfeeding.

This paper aims to present key information about the $\mathrm{WBC} i$ initiative, and to summarize findings about the potential cost of implementing the Global Strategy more widely.

\section{Methods for costing of interventions}

\section{Data, scope, and costing approach}

WBC $i$ takes a programmatic approach to scaling up interventions in 214 countries, basing costs on either national amounts allocated to the intervention or on globally accepted costs. The costings are of direct, mainly financial costs from a governmental perspective [30-32]. All financial estimates are US dollars.

The estimate of financial outlays includes:

- One-off costs such as developing IYCF policies, and legislation on the International Code, and;

- Recurring costs such as: training of health workers and community volunteers in skilled counselling and implementing the International Code, media campaigns, maternity protection and monitoring of implementation.

\section{Unit cost and total cost calculations}

For calculating the unit cost for each intervention, the following steps were taken:

1. The unit cost was calculated for the country, that is, the data source.

2. The unit costs for the Baby Friendly Hospital Initiative (BFHI), mass media communication, legislating the International Code and community support for breastfeeding/IYCF have been taken from available published data (see Table 2). Where no published data was available, the median of costs budgeted by countries was computed based on information from colleagues and officials in relevant ministries in Brunei Darussalam, China, Egypt, Fiji, India, Mongolia, Saudi Arabia, Rwanda, Brazil and Australia.

3. Unit costs were adjusted for inflation to 2012 using the published World Bank inflation rates [33].

4. The inflation adjusted unit cost was converted into US dollars. ${ }^{i}$

5. Some costs were converted into international dollars using the World Bank purchasing power parity (PPP) conversion factors for 2012 [34]. These items were: 1 ) breastfeeding training for health workers; 2 ) community counselling incentives; 4) media promotion, and; 5) BFHI implementation.

6. Other costs, for policy development and review, drafting of a national code, legislation development and maternity entitlements, were computed using the currency exchange rate.

7. The PPP was available for 167 countries; where unavailable the local currency was converted into US dollars at the annual exchange rate.

8. The total cost for the intervention was calculated by the multiplying the unit cost by the global birth cohort, for 194 countries in the State of the World's Children 2013 (SOWC [35]).

9. The price per child was derived indirectly using the adjusted unit cost. Data on the birth cohort is taken from SOW [35]. (While UNICEF data lists only 194 countries, the remaining 20 countries and territories are small, and birth cohorts are unlikely to be large relative to other included countries. We anticipate that the difference in total costs and cost per live birth will be minimal).

10. For calculating the estimate on maternity entitlements, we have allocated a minimum of $\$ 2 /$ day per target recipient. This was done keeping in view the minimum sum required to survive as per World Bank estimates [36]. The number of households under the poverty line is estimated from SOWC [35].

\section{Overhead and capital infrastructure costs excluded}

The necessary delivery platforms for the Global Strategy are the following:

- Health facilities;

- Community health and nutrition programs and home deliveries;

- Mother support groups/family level communication.

We have not included overhead costs (for example, administration salaries) or capital costs of delivery systems 
Table 2 Global financial resources creating the enabling environment for optimal breastfeeding

\begin{tabular}{|c|c|c|c|c|c|c|}
\hline \multicolumn{2}{|c|}{ Total target (live births only) 214 countries } & \multicolumn{5}{|c|}{$135,000,000$} \\
\hline \multicolumn{2}{|c|}{ Total population } & \multicolumn{5}{|c|}{167 countries } \\
\hline \multicolumn{2}{|c|}{ No. of women living below the poverty line } & \multicolumn{5}{|c|}{$35,200,684$} \\
\hline \multicolumn{2}{|c|}{ Country with legislated international code } & \multicolumn{5}{|l|}{ [33] } \\
\hline \multicolumn{2}{|l|}{ Total number of countries } & \multicolumn{5}{|l|}{214} \\
\hline \multicolumn{2}{|c|}{$\%$ of Births assisted in health facility } & \multicolumn{5}{|l|}{$61 \%$} \\
\hline Description & $\begin{array}{l}\text { What is included in } \\
\text { the cost }\end{array}$ & Unit & $\begin{array}{l}\text { No. of } \\
\text { Units }\end{array}$ & $\begin{array}{l}\text { Total Cost of } 214 \\
\text { countries (\$) }\end{array}$ & $\begin{array}{l}\text { Cost per live } \\
\text { birth } \$\end{array}$ & Reference \\
\hline \multicolumn{7}{|l|}{ One-time costs } \\
\hline \multirow[t]{5}{*}{$1 / Y$} & 1. Meetings & \multirow[t]{5}{*}{ Country } & \multirow[t]{5}{*}{214} & \multirow[t]{5}{*}{$5,350,000$} & \multirow[t]{5}{*}{$\$ 0.04$} & Median Cost of 3) countries: \\
\hline & $\begin{array}{l}\text { 2. WBTi review and } \\
\text { analysis from } \\
\text { IBFAN with } \\
\text { discussions }\end{array}$ & & & & & 1) Afghanistan \\
\hline & $\begin{array}{l}\text { 3. Data processing } \\
\text { and analysis }\end{array}$ & & & & & 2) Fiji \\
\hline & $\begin{array}{l}\text { 4. Consultations and } \\
\text { drafting sessions }\end{array}$ & & & & & 3) Mongolia \\
\hline & 5. Consultant & & & & & \\
\hline \multirow[t]{7}{*}{ International code } & $\begin{array}{l}\text { Drafting and } \\
\text { Legislative process }\end{array}$ & \multirow[t]{7}{*}{ Country } & \multirow[t]{4}{*}{181} & \multirow[t]{4}{*}{$9,050,000$} & \multirow[t]{4}{*}{$\$ 0.07$} & \multirow[t]{4}{*}{$\begin{array}{l}\text { Median Cost, four (4) countries: 1) China } \\
\text { 2) Egypt 3) Fiji 4) Afghanistan }\end{array}$} \\
\hline & 1. Meetings & & & & & \\
\hline & 2. Discussions & & & & & \\
\hline & $\begin{array}{l}\text { 3. Consultations and } \\
\text { drafting sessions }\end{array}$ & & & & & \\
\hline & Legislative Process & & 181 & $470,600,000$ & $\$ 3.49$ & {$[37]$} \\
\hline & $\begin{array}{l}\text { 1. Parliamentary/ } \\
\text { congress/ } \\
\text { legislative process } \\
\text { (sessions, } \\
\text { committees and } \\
\text { plenary debates) }\end{array}$ & & & & & \\
\hline & & & Subtotal 1 & $485,000,000$ & $\$ 3.60$ & \\
\hline \multicolumn{7}{|c|}{ Annual cost (Recurrent) (Ministry of health, nutrition) } \\
\hline \multirow[t]{3}{*}{ BFHI Implementation } & 1. Bed in & \multirow[t]{3}{*}{ Country } & \multirow[t]{3}{*}{214} & \multirow[t]{3}{*}{$2,010,000,000$} & \multirow[t]{3}{*}{$\$ 15$} & [38], adjusted to International US \$ \\
\hline & $\begin{array}{l}\text { 2. Health education } \\
\text { to mothers }\end{array}$ & & & & & \\
\hline & $\begin{array}{l}\text { 3. No formula in the } \\
\text { facility }\end{array}$ & & & & & \\
\hline $\begin{array}{l}4 \text { Training of health } \\
\text { workers }\end{array}$ & $\begin{array}{l}\text { 1. Breastfeeding } \\
\text { training for health } \\
\text { workers (nurses, } \\
\text { midwives) }\end{array}$ & Country & 214 & $251,000,000$ & $\$ 2$ & [39] \\
\hline 5 Community support & $\begin{array}{l}\text { Incentive and } \\
\text { training for } \\
\text { community } \\
\text { volunteers }\end{array}$ & Country & 214 & $1,340,000,000$ & $\$ 10$ & {$[28]$} \\
\hline 6 Media promotion & $\begin{array}{l}\text { Cost of media } \\
\text { (radio) advertising }\end{array}$ & Country & 214 & $723,000,000$ & $\$ 5$ & [40] \\
\hline 7 & & Country & 214 & $11,769,615$ & $\$ 0.10$ & India training experience \\
\hline
\end{tabular}


Table 2 Global financial resources creating the enabling environment for optimal breastfeeding (Continued)

\begin{tabular}{|c|c|c|c|c|c|c|c|}
\hline & $\begin{array}{l}\text { Training on the } \\
\text { international code }\end{array}$ & $\begin{array}{l}\text { Five (5) day training } \\
\text { on 1) understanding } \\
\text { and 2) monitoring } \\
\text { the International } \\
\text { Code }\end{array}$ & & & & & \\
\hline \multirow[t]{2}{*}{8} & Monitoring & $\begin{array}{l}\text { Monitoring the } \\
\text { implementation of } \\
\text { the different } \\
\text { programs } \\
\text { (International code, } \\
\text { BFHI, community) }\end{array}$ & Country & 214 & $81,000,000$ & $\$ 0.60$ & [28] \\
\hline & & & & Subtotal 2 & $4,414,800,000$ & $\$ 33$ & \\
\hline \multicolumn{8}{|c|}{ Annual cost (Ministry of labor, social security system ministry of finance, Ministry of social welfare } \\
\hline \multirow[t]{3}{*}{9} & Maternity entitlements & $\begin{array}{l}\text { Allowance for } \\
\text { women living below } \\
2 \$ / \text { day for a period } \\
\text { of six months }\end{array}$ & Country & 214 & $12,700,000,000$ & 94 & $\begin{array}{l}2 \cup \$ / \text { day as a minimum entitlement } \\
\text { based on the poverty line set by } \\
\text { World Bank }\end{array}$ \\
\hline & & & & Subtotal 3 & $12,700,000,000$ & 94 & \\
\hline & & & & Total & $\$ 17,601,800,000$ & 130 & \\
\hline
\end{tabular}

for health services and other social and economic infrastructure in our estimates. These differ widely from country to country, and countries are assumed to have this basic delivery capacity.

The public sector health and the nutrition delivery system, with its community outreach programs that reach out to families regularly for antenatal check-ups, distribution of iron and folic acid tablets, tetanus toxoid injections during pregnancy, weighing and growth monitoring of infants and young children and immunization, are already equipped with human resources and transport facilities. We assume that with an additional component of training in skilled counselling, this cadre of workers will deliver the required services.

It is assumed that the government health and nutrition sector and the general public will monitor implementation of the International Code and the regulatory machinery of the government will have enforcement capacity. For provision of maternity benefits, the costings assume that various sectors of the governance system - health and nutrition sector, labor, welfare sectors - as well as the general public will monitor the implementation of maternity legislation and ensure that action is taken against violations.

Finally, the government is taken to administer the disbursal of financial benefits through existing structures and systems adapted to local conditions, at zero or minimal additional cost.

\section{Non market economic goods and services excluded}

Considering community based or volunteer mother-tomother support groups, we have assumed the existence and capacity of community volunteer groups, who will be given training and some financial incentives for counselling, but we have not fully budgeted most costs, or the organizational costs for developing, maintaining and expanding breastfeeding support groups. (The value of these volunteer contributions may be several times the financial contribution from government, based on unpublished estimates for Australia). We did not estimate the economic cost to women of additional time spent breastfeeding.

We estimated costs for the following categories of action. Table 2 sets out details of the costings in these categories.

\section{Main cost categories}

Development of optimal breastfeeding strategies, policies and plans, and coordination

Effective policies are based on adequate planning and policy development processes, and coordination of relevant policies and services. The Global Strategy is presented as an integrated and comprehensive program, and such an approach has been found to be effective in achieving better breastfeeding practices [41]. In consequence the WBC $i$ costing include the costs of hiring national and international consultants, holding workshops and consultations, developing documents, building consensus, printing and dissemination, multi-sectorial coordination and regular review and analysis of the progress made in implementing the agreed plan using the WBTi tool. The estimate is based on the unit cost worked out as a median of the costs of this activity in Afghanistan, Fiji and Mongolia. While policy making is treated as a one-off cost, monitoring and review are considered annual recurrent costs. 


\section{Implementing the international code of marketing of breastmilk substitutes}

An important element of the Global Strategy is to constrain inappropriate marketing and consumption of breast milk substitutes (BMS) including milk formula for infants and toddlers. In response to concern about unregulated marketing of BMS and potential detrimental effects on infant and child mortality, the International Code was adopted at the World Health Assembly in 1981 by 118 member states. A recent review by WHO found that in 2012 only 37 of 199 countries (19\%) had fully implemented the International Code including by legislation [42].

The WBCi estimate includes three components - drafting the law, law making and training in International Code implementation. While the former two are one-time costs, the latter is a recurring cost. The estimate covers the cost of hiring national and international consultants, holding workshops and consultations, advocacy and building consensus, cost of the passage of the law through the legislature and training a cadre of government officials in recognizing violations, monitoring adherence and initiating action in case of violations. The estimate does not include the costs involved in any legal or judicial action in the case of violations.

\section{Drafting national legislation to implement the international code}

This estimate is the median of the costs incurred in Afghanistan, China, Egypt and Fiji.

\section{Law making to implement the international code}

In 2012 Wilson and colleagues estimated based on a study in New Zealand, that $\$ 2.6$ million is needed to pass a public health law [37]. We have used this figure as the unit cost of legislating the International Code.

\section{Training for officials and others on the National Code/ Legislation}

The one-off costs of training of 200 officials over five years is based on 2-day training workshops held in India, at $\$ 23,160$ per training (actual cost of training workshops). The costs of training field level workers was not estimated, it was assumed that the skill training course provided will include a component on the International Code (national measure). For subsequent monitoring of violations we have used the estimation by Breastfeeding Promotion Network of India of $\$ 1927$ per district with a population of 1-2 million [43].

\section{Baby Friendly Hospital Initiative (BFHI) implementation, and} health worker training

The health care system itself has been used as an avenue to promote formula feeding and undermine breastfeeding, and recent studies point to targeting of health workers by industry. Recent media reports have highlighted corrupt and unethical promotion of formula feeding through hospitals and health professionals in China $[44,45]$. This has also been demonstrated historically for Australia [46], and in the Philippines where a recent study by WHO found that health workers were targeted by company promotions, and these were highly influential in leading mothers to initiate formula feeding [47]. This WBCi cost category has two components, full implementation of the WHO/ UNICEF BFHI, and training of health workers:

\section{BFHI (Ten Steps to Successful Breastfeeding)}

The cost includes developing a hospital policy, its dissemination, appropriate training of hospital staff (nurses, lactation counsellors), skilled counselling and support at birth and during the stay of mothers. The unit cost is based on the results from the study conducted through maternity services in Brazil, Honduras and Mexico for estimating the costs and impact of breastfeeding promotion programs [48]. The suggested costs to eliminate infant formula, to practise rooming-in and the cost per birth for maternal education activities within the health facility, including their training were combined. The cost per birth assisted in a health facility (61\%), was used to estimate the costs for health facilities with maternity services to implement the 10 steps for successful breastfeeding.

\section{Training public health workers}

The unit cost was calculated from the cost of replicating the LINKAGES LAM Promotion Program in Jordan from December 2001-2002 [39], and was adjusted for inflation. The estimate includes costs of training of midwives, public health nurses and other health workers who conduct deliveries at homes and provide counselling and other services as part of the health system's services.

\section{Community services and mother-to-mother support}

Practical and well informed support for breastfeeding in the community is crucial and cannot be taken for granted. The WBCi estimate uses costs of such community services as calculated by Mason [49], adjusted for inflation to 2012. It includes training of field workers (community based/peer counsellors), volunteers and mother support groups providing counselling services at the household level in the community, as well as some incentives provided from the health and nutrition system. We have further included a unit cost per live birth for refresher courses, based on actual expenses incurred by the BFCHI Project in Lalitpur, India. ${ }^{\text {ii }}$

\section{Media promotion/social marketing}

The WBCi estimates include the cost of breastfeeding promotion programs using mass and local media to 
counter industry messages undermining breastfeeding on an on-going basis ('social marketing') [50]. The general principle should be that investment in breastfeeding promotion should match that by the industry in the same market; effective enforcement of the International Code through regulation would help lower such government 'social marketing' costs [51]. A typical rule of thumb for industry is a marketing expense of $10 \%$ of gross sales value [52], more in highly competitive industries such as pharmaceutical industries, less in stable markets [53]; an estimate in this range is supported by a recent WHO study in the Philippines [54]. We have therefore estimated the cost of radio campaigns at $\$ 5$ per child, as recommended in the World Bank's report No. WPS 952 in 1992 [40]. The amount per child has been adjusted for inflation to 2012 .

\section{Monitoring}

This estimate includes the cost of monitoring the implementation of the interventions, including development of the national policy and plan of action, the national law that implements the International Code, BFHI, etc., review meetings, updating of policies and plans and operational research. The estimate in Scaling Up Nutrition of $\$ 200$ million for the monitoring and evaluation of interventions that target 326 million children, is used to compute the cost per beneficiary. As most countries are already conducting national surveys on breastfeeding practices, this cost was not taken into account.

The financial resources needed for conducting national assessments of implementation of the Global Strategy using WBT $i$ were estimated [55]. Currently 82 countries from Asia, Latin America, the Caribbean and Africa are utilizing this tool to track and monitor their implementation of the Global Strategy and identify gaps. The cost per country for using this tool and building consensus over the assessment and identification of gaps, developing report cards and national reports, is about $\$ 4000$, which includes country cost of minimal expenses and project costs at the regional level.

\section{Maternity leave protection}

An important non-market economic cost of breastfeeding is the potential economic opportunity cost of the mother's time spent exclusively breastfeeding [56-59]. This points to the importance of paid maternity leave policies, which have been shown to correlate with substantially higher breastfeeding rates in a recent global study [60]. In the $\mathrm{WBC} i$, a flat rate of $\$ 2$ per day/mother for 180 days is costed as financial assistance for women living below the poverty line. Providing a woman with this amount is assumed to offset some economic costs to the mother and her family by enabling her to stay in necessary proximity to her newborn for longer with six months of exclusive breastfeeding. We have not computed the costs of provision of maternity benefits for women working in the formal sector as these vary widely from country to country, both in amount and in the source of financing. We have not estimated the cost of setting up crèches, or of workplace accommodations needed by employed mothers of infants and young children to ensure their proper care and feeding.

\section{Results}

\section{Global costs}

Table 2 gives the estimated cost per intervention and aggregate costs.

Using the WBCi costing tool, the cost of implementing the Global Strategy program for 214 developing countries is estimated at $\$ 17.6$ billion.

\section{Recurring costs}

Importantly the major recurring cost is maternity entitlements. The global cost of implemented a minimum entitlement based on the World Bank poverty line is $\$ 12.6$ billion. This highlights that initiatives to protect, promote and support breastfeeding will need to address the economic implications for women to be successful. While breastfeeding has less financial cost to the mother, the need for proximity to the infant and for 'breastfeeding friendly' workplaces and childcare, can be a barrier to maternal employment and income earning activities. As employment and childcare arrangements may be inflexible to the needs of breastfeeding mothers, paid maternity leave policies and related measures are increasingly essential for countries experiencing rapid economic growth and employment opportunities.

\section{Other major costs}

Other major cost items are implementation of the BFHI which accounts for $\$ 2.1$ billion of the total cost, and Community Support which accounts for $\$ 1.3$ billion of this cost.

\section{Discussion}

The WBCi is a landmark first attempt to cost the implementation of the Global Strategy in its entirety and integrate it into other global nutrition initiatives notably the World Bank initiative, Scaling Up Nutrition [28]. The World Bank report noted the staggering cost of undernutrition worldwide, and the loss of billions of dollars in foregone productivity and avoidable health care spending. The public funding resources of $\$ 11.8$ billion annually said to be needed to counter the problem included increasing breastfeeding as one of the 13 proven nutrition interventions. However, these costings made inadequate provision for breastfeeding, providing only for programs of 'behaviour change' but without addressing the key structural 
barriers to optimal breastfeeding, especially the time pressure and labour market barriers to breastfeeding, and the health services, community support, and marketing issues identified by the Global Strategy and related initiatives.

The WBCi focusses on redressing such costing gaps, and the major finding of the global analysis using the WBCi tool is that the financial cost of implementing the WHO/UNICEF Global Strategy for 214 developing countries is in line with the cost of such major global nutrition initiatives. One-off costs of initiating implementation globally are around $\$ 485$ million, while the recurrent costs including maternity protection are $\$ 17.1$ billion. Other significant costs are associated with BFHI implementation, and improving community based support for breastfeeding.

The WBCi costing is likely to underestimate actual costs of implementing the Global Strategy in its entirety worldwide, as unit costs have been based on the few available estimates, mainly from developing countries; these estimates are clearly lower than if the same interventions were budgeted for in developed countries which are likely to have higher costs. On the other hand it may overestimate costs if a strong regulatory approach is taken. For example, costs of social marketing expenditures and health worker training could be minimized by strong legislation addressing inappropriate marketing and promotion of breastmilk substitutes.

The accuracy of the estimates is clearly most sensitive to assumptions for the three major cost areas. For example, raising the level of the maternity entitlement by $20 \%$ to $\$ 2.40$ a day would add some $\$$ US2.5 billion to the $\$$ US17.6 billion cost. Likewise, if BFHI implementation unit costs were taken to be $\$ \mathrm{US10}$ rather than \$US15 (for example, to partly account for potentially offsetting lower current and future health system costs), the cost of BFHI implementation would be reduced by $\$ \mathrm{US670}$ million to around \$US1.3 billion. Increasing the budget for incentives and training for community volunteers (the third largest cost item) by $20 \%$ would add just $\$$ US270 million to the overall cost.

The cost analysis also provides a figure that draws attention to the offsetting benefits of improved breastfeeding rates. Several economic studies have shown the high economic value of breastfeeding, both in reducing burdensome family expenditures on breast milk substitutes or avoidable health costs, and in increasing the production of human milk [10-13,15,18,24,25,57,61-63]. At prices currently paid in developed countries of over $\$ 85$ per litre, the global economic value of breast milk production, if optimal breastfeeding were achieved for $95 \%$ of infants and young children, has been estimated to be more than $\$ 3,380$ billion a year [9]. Using the methodology in such studies, this suggests an economic gain of nearly $\$ 1,400$ billion a year comparative to current levels. By comparison with the financial outlay to implement the Global Strategy, the potential economic and other benefits of improved breastfeeding rates are high.

The analysis highlights also that as no country has yet substantially implemented the Global Strategy, or budgeted for its implementation, little has been done worldwide to facilitate optimal breastfeeding.

The fundamental premise of this paper is that access to interventions to achieve optimal IYCF practices (breastfeeding and complementary feeding) is a right of every woman and child [64]. Each woman who gives birth requires an enabling environment to achieve optimal breastfeeding. Our study focuses on financial costs to the government sector and does not directly account for personal or household costs of breastfeeding which may include foregone maternal earnings, career opportunities, or other maternal constraints.

There are wider benefits for maternal and child health and well-being from an initiative for maternity entitlements, beyond breastfeeding, such a program would help address poverty among women as a source of inequitable access to optimal breastfeeding. Program benefits could be reinforced by labour market regulations giving employers and childcare services appropriate incentives to support optimal breastfeeding amongst employed mothers. This approach acknowledges the real economic costs and time constraints of optimal breastfeeding to households and to women in particular: as noted earlier, research in developed and developing country settings has shown that exclusive breastfeeding can be very time costly if appropriate support for lactation is not available in work environments and childcare services.

\section{Strengths and limitations}

The unique strengths of this study and the research that underpins it are that it provides both conceptual and practical advances which can inform global, country level, and community efforts to implement the Global Strategy. This includes its strong and comprehensive conceptual basis:

1. being structured around evidence based interventions that would contribute to the improvement of optimal breastfeeding practices;

2. based on strategies and interventions that government and developmental partners are implementing at the national and sub-national level;

3. contributing a novel initial framework to estimate the resources necessary to be invested to implement the above;

4. Conceptually comparable with estimates of the economic value of breastfeeding, and the health system benefits of optimal IYCF. 
Its other strengths are that its design and development includes a platform to share country experiences on investing and an opportunity to identify data/information gaps that may need to be addressed with more research in the area. The research further contributes by providing a priority research agenda on IYCF for initiatives by international and national agencies such as on maternal and child nutrition. It can also help the global community to move beyond the need to invest on commodities and to include programmatic aspects in their investments.

Limitations of our study include that up to date research to underpin program level cost estimates on reducing suboptimal IYCF is sadly lacking; there is an urgent need to update and extend previous economic studies on interventions to increase breastfeeding such as those by Horton and colleagues [40,48]. The World Bank has provided strong standardized unit cost data for IYCF promotion in Scaling Up Nutrition; however, more detailed cost data from recent fieldwork is crucial for implementation of the range of known effective interventions for increasing breastfeeding.

Apart from this major consideration, the financial resources estimated in this document have the following specific limitations:

1. Lack of data on birth cohorts and number of households below the poverty line in 20 countries and territories.

2. Wide divergence between staff responsibilities, salaries, transport costs and infrastructure costs among nations. Thus, while the interventions require an increase in human resources and the resultant financial resources in most countries, we did not attempt to cost either the number of staff required nor staff salaries.

3. Limited information on the kind of maternity protection and maternity entitlements that are being offered to women working in the unorganized/ informal economy, as well as to homemakers in households below the poverty line, in several countries. Also lack of robust information on any incentive effects on maternal labour force behaviour that would need to be included in a full economic costing model.

4. The costs of other direct and indirect interventions that impact optimal breastfeeding practice, such as food supplementation for mothers and children, including micronutrients and foods for preventing and managing malnutrition, special needs of infants in the context of HIV/AIDS, were not estimated.

5. Our estimates are also fundamentally constrained by cost estimates being from the health agency/ government perspective. While limited maternity protection costs are included, the perspective taken excludes the unpaid household sector, and therefore in particular, any additional economic costs to mothers, or to those working for volunteer organizations and groups providing necessary services and activities underpinning community based, mother to mother support for breastfeeding.

6. Assuming constant returns to scale. There may be economies of scale or the program may get more complex as it is scaled up.

\section{The WBCi financial planning tool}

The WBCi costing analysis also highlights the need for countries to estimate more accurately the costs of implementing the Global Strategy in their context and illustrates the importance and potential value of using the $\mathrm{WBCi}$ Financial Planning Tool for country specific analysis.

The WBCi, a milestone initiative of IBFAN Asia, has been developed following the principles and structure of the WBT $i$ tool to help countries track the implementation of the Global Strategy and identify gaps in its implementation. The WBCi tool is a user-friendly MS Excel tool to help countries comprehensively estimate the resources necessary to implement the policy and programs proposed by the Global Strategy, as well as specific detailed plans to bridge the gaps identified by WBTi and budget them adequately and accurately according to local conditions. It can be used to generate annual IYCF financial plans, multi-year estimates, and budget proposals, using local estimates, inputs and information.

The WBC $i$ Financial Planning Tool [65] can be used to conduct studies at the individual country level and global level. It can be contextualized at the country level through simple key parameters, such as exchange rates and unit costs or salary levels, chosen by the user.

The WBC $i$ tool is intended for national program managers and partners to initiate a constructive and productive advocacy with national governments and donors, towards the identification and allocation of the financial and human resources necessary to protect, promote and support optimal breastfeeding and complementary feeding practices in the country. It may also be used to track budgets.

The key features of the tool include the following:

- Customization of the cost, using the most recent national data;

- Generation of individual cost for the key interventions recommended by the Global Strategy;

- Tracking estimates $v s$. actual resources provided by government and donors;

- Generation of reports for discussions and presentations to other stakeholders;

- Review and update cost estimates based on program monitoring and evaluation. 
The WBCi tool has been successfully used by Department of Nutrition, Ministry of Public Health, Afghanistan, to budget and raise funds for specific actions such as celebration of the World Breastfeeding Week, as well as broader programs such as training of health professionals and field workers in counselling skills. ${ }^{\text {iii }}$

\section{Conclusions}

The WHO's scientific analysis of benefits of breastfeeding on child health and development, extending well into adult life and increasing IQ, cannot be ignored, nor can the evidence of its impact on reducing infant and child mortality and malnutrition, and its importance for maternal reproductive health. However, demonstration of the budgetary feasibility and sustainability and potential economic gains from the Global Strategy is important to its practical implementation. The time has come to transform the token attention breastfeeding often receives into a non-negotiable commitment to the full implementation of the Global Strategy through multi-sectoral action, rather than the implementation of only a few interventions.

In order to breastfeed successfully, women must have access to all the services that protect, promote and support breastfeeding. Women need to be physically close to their infants and to be confident about their ability to feed their infants adequately. They should also be free from pressure by the milk formula manufacturers so as to make good infant feeding decisions. This may require strict enforcement of the International Code of Marketing of Breastmilk Substitutes and/or national laws, and behaviour change that can be achieved through skillful counselling, ideally during pregnancy and at family level. Interventions that provide protection from commercial sector competition and support at health facilities and in the workplace are vital.

The 'market' and the incentives it creates cannot be relied on to protect, promote and support breastfeeding, as is well illustrated by economic analysis of 'market failures' in this area $[7,8]$. Governments and international agencies have a responsibility to ensure resources commensurate with the benefits of optimal breastfeeding. Global and national attention should be visible, especially in terms of making financial resources available within and to countries. With the problem of malnutrition increasing worldwide as obesity adds to problems of under-nutrition, decisive action on IYCF is urgently needed.

The following is a set of recommendations to move forward:

\section{Governments (and relevant agencies as appropriate) should}

1. Plan and budget for the comprehensive global and national implementation of the Global Strategy, and integrate its implementation as part of national development and economic priorities.

2. Conduct policy and program assessments on breastfeeding and IYCF using WHO assessment tools or WBT $i$ tools in order to identify and document gaps.

3. Develop or assist development of national and sub-national action plans for 1-5 years with clear budgets to achieve results, based on the policy gaps found.

4. Develop or assist development of national/regional/ provincial-monitoring and periodic reporting systems on optimal breastfeeding practices.

5. Institutionalize research to document benefits of this program to populations, in terms of disease reduction and long term health as well as cost savings.

6. Report annually on the key expenditures incurred on interventions for optimal breastfeeding and track intervention progress, in all major areas of action noted above.

7. Take urgent action on policy matters such as maternity leave and other measures.

\section{The global community should}

1. Allocate specific budgets for increasing optimal breastfeeding within existing global funds for child survival, nutrition and health (All donors and global agencies).

2. Revisit estimates on Scaling Up Nutrition, giving full consideration to all interventions required for universal services to facilitate optimal breastfeeding. (World Bank).

3. Make a priority commitment for universal application of the International Code and IYCF (WHO, UNICEF, World Bank).

4. Report annually the money spent on programs on improving policy and programs for optimal breastfeeding (All agencies).

5. Setup a special maternity benefit fund for cash assistance to women below the poverty line (World Bank).

\section{Endnotes}

i. "An international dollar is hypothetical currency that is used as a means of translating and comparing costs from one country to the other using a common reference point, the US dollar. An international dollar has the same purchasing power as the US dollar has in the United States. Costs in local currency units are converted to international dollars using purchasing power parity (PPP) 
exchange rates" (source: WHO CHOICE: http:// www.who.int/choice/costs/prog_costs_intro/en/ ii. Personal communication from Dr. K.P. Kushwaha, 19 September 2012.

iii. Personal communication, Dr H Ludin, Ministry of Public Health, Afghanistan.

\section{Competing interests}

The authors declare that they have no competing interests. No specific sources of funding were used in the writing of this article.

\section{Authors' contributions}

$\mathrm{RH}$ and JPS wrote the manuscript. AG, JD and Al and JPS provided draft revision. All authors read and revised the manuscript critically for important intellectual content and approved the final manuscript.

\section{Acknowledgements}

We would like to acknowledge with gratitude the support and guidance given by Dr. Francesco Branca and Dr. Tommaso L. Cavalli Sforza of the World Health Organization in preparation of the original study, and the many in various national health and other organizations who helped with financial estimates from their countries or guided us on where to find such information: Mrs Ateca Kama, Ministry of Health, Fiji; Dr. Soyolgerel Gochoo, Mongolia; Ms Rosemary Lilu Kafa, Solomon Islands; Dr. Shuyi Zhang, China; Dr. Gihan Fouad, Egypt; Dr. Albandri Abonayan, Saudi Arabia; Mrs Roseyati Yakuub, Brunei Darussalam; Dr. K.P. Kushwaha, India; Ms Nemat Hajeebhoy, Vietnam; Ms Christine Namatovu, Uganda; and Dr. Seema Mihirshahi, Australia. IBFAN regional coordinators Marta Trejos, Joyce Chanetsa and Elizabeth Sterken assisted with information on status of policies and legislation in countries in their region. Dr. Susan Horton, Canada, Dr. Adriano Cattaneo, Institute of Child Health, Italy, Dr. Lida Lhotska, IBFAN/GIFA, Dr. Meera Shekar, World Bank, and Dr. Urban Jonsson, Tanzania also assisted with review and guidance. Ashi Kohli Kathuria and Mohini Kak provided guidance on the World Bank funding process. The project was possible through financial support from SAFANSI (South Asia Food and Nutrition Security Initiative) project and a contribution by DFID (Department for International Development) and AusAID (Australian Agency for International Development). Sida and Norad helped with the dissemination.

\section{Author details}

'International Baby Food Network (IBFAN) Asia, BP 33 Pitampura, New Delhi, India. ${ }^{2}$ BBFAN Asia, 4535a Casino St, Palanan Makati, Metro Manila, Philippines. ${ }^{3}$ Australian National University, Canberra, Australia. ${ }^{4}$ Breastfeeding Promotion Network of India, BP 33 Pitampura, New Delhi, India.

Received: 2 June 2014 Accepted: 21 January 2015 Published online: 23 February 2015

\section{References}

1. World Health Organization (WHO). Global Strategy for Infant and Young Child Feeding. Geneva, Switzerland: World Health Organization; 2003.

2. Jones G, Steketee RW, Black RE, Bhutta ZA, Morris SS, Bellagio Child Survival Study Group. How many child deaths can we prevent this year? Lancet. 2003;362:65-71.

3. Lamberti LM, Zakarija-Grković I, Walker CLF, Theodoratou E, Nair H, Campbell $\mathrm{H}$, et al. Breastfeeding for reducing the risk of pneumonia morbidity and mortality in children under two: a systematic literature review and meta-analysis. BMC Public Health. 2013;13 Suppl 3:S18.

4. Horta BL, Victora CG. Long-term Effects of Breastfeeding. Geneva: World Health Organization; 2013.

5. Debes AK, Kohli A, Walker N, Edmond K, Mullany LC. Time to initiation of breastfeeding and neonatal mortality and morbidity: a systematic review. BMC Public Health. 2013;13 Suppl 3:S19.

6. Euromonitor. Passport Database. 2012. http://www.euromonitor.com/ passport\#

7. Frick KD. Use of economics to analyse policies to promote breastfeeding. In: Dykes F, Moran V, editors. Infant and Young Child Nutrition, Multicultural Challenges to Implementing a Global Strategy. Oxford: Wiley-Blackwell; 2009. p. 181-96. 181-196.

8. Smith JP. Mothers' milk and markets. Aust Fem Stud. 2004;19:369-79.
9. Smith JP: Including household production in the System of National Accounts (SNA) - Exploring the implications of breastfeeding and human milk provision, ACERH Working Paper, No. 10, http://www.acerh.edu.au/ publications/ACERH_WP10.pdf; 2012.

10. Smith JP. Human milk supply in Australia. Food Policy. 1999;24:71-91.

11. Gupta A, Khanna K. Economic value of breastfeeding in India. Natl Med J India. 1999;12:123-7.

12. Oshaug A, Botten G. Human milk in food supply statistics. Food Policy. 1994;19:479-82.

13. Aguayo VM, Ross J. The monetary value of human milk in Francophone West Africa: a PROFILES analysis for nutrition policy communication. Food Nutr Bull. 2002;23:153-61.

14. Bhutta ZA, Das JK, Rizvi A, Gaffey MF, Walker N, Horton S, et al. Evidence-based interventions for improvement of maternal and child nutrition: what can be done and at what cost? Lancet. 2013;382:452-77.

15. Smith JP. "Lost Milk?" counting the economic value of breast milk in gross domestic product. J Hum Lact. 2013;29:537-46.

16. Bhandari N, Kabir A, Salam MA. Mainstreaming nutrition into maternal and child health programmes: scaling up of exclusive breastfeeding. Matern Child Nutr. 2008;4:5-23.

17. Bhutta ZA, Ahmed T, Black RE, Cousens S, Dewey K, Giugliani E, et al. What works? Interventions for maternal and child undernutrition and survival. Lancet. 2008:371:417-40.

18. Caulfield LE, Richard SA, Rivera JA, Musgrove P, Black RE. Stunting, wasting, and micronutrient deficiency disorders. In: Jamison DT, Breman JG, Measham AR, Alleyne G, Claeson M, Evans DB, Jha P, Mills A, Musgrove P, editors. Disease Control Priorities in Developing Countries. 2nd ed. New York: Oxford University Press; 2006.

19. Lutter CK, Morrow AL. Protection, promotion, and support and global trends in breastfeeding. Adv Nutr Int Rev J. 2013;4:213-9.

20. Gupta A, Dadhich J, Suri S. How can global rates of exclusive breastfeeding for the first 6 months be enhanced? ICAN Infant Child Adolesc Nutr. 2013;5:133-40

21. UNICEF. Breastfeeding on the Worldwide Agenda. New York: New York United Nations Children's Fund; 2013.

22. Gupta A, Holla R, Dadhich J, Bhatt B. The World Breastfeeding Trends Initiative (WBTi). Are our Babies Falling Through the Gaps? The State of Policies and Programme Implementation of the Global Strategy for Infants and Young Child Feeding in 51 Countries. New Delhi, India: BPNI/IBFAN Asia; 2012

23. World Health Organization (WHO). International Code of Marketing of Breastmilk Substitutes. Geneva: World Health Organization (WHO); 1981.

24. Bartick M, Reinhold A. The burden of suboptimal breastfeeding in the United States: a pediatric cost analysis. Pediatrics. 2010;125:e1048.

25. Renfrew MJ, Pokhrel S, Quigley M, McCormick F, Fox-Rushby J, Dodds R, et al. Preventing Disease and Saving Resources; the Potential Contribution of Increasing Breastfeeding Rates in the. UK: UNICEF UK; 2012.

26. Smith JP, Thompson JF, Ellwood DA. Hospital system costs of artificial infant feeding: estimates for the Australian Capital Territory. Aust N Z J Public Health. 2002;26:543-51.

27. Mutuma S, Fremont E, Adebayo A. Aid for Nutrition: can Investments to Scale up Nutrition Actions be Accurately Tracked. London: Action Against Hunger; 2012.

28. Horton S, Shekar M, McDonald C, Mahal A, Krystene Brooks J. Scaling Up Nutrition: What Will It Cost? Washington, DC: World Bank; 2010.

29. Holla R, lellamo A, Gupta A, Dadhich JP, Smith JP. The Need to Invest in Babies - A Global Drive For Financial Investment in Children's Health and Development Through Universalizing Interventions for Optimal Breastfeeding. Delhi, India: Breastfeeding Promotion Network of India (BPNI)/International Baby Food Action Network (BBFAN)-Asia; 2013.

30. Gold MR, Siegel JE, Russell LB, Weinstein MC. Cost-Effectiveness in Health and Medicine. Report of the Panel on Cost-Effectiveness in Health and Medicine. New York: Oxford University Press; 1996.

31. Drummond MF. Guidelines for authors and peer reviewers of economic submissions to the BMJ. Br Med J. 1996;313:275-83.

32. Drummond MF, Sculpher MJ, Torrance GW, O'Brien BJ, Stoddart GL. Methods for the Economic Evaluation of Health Care Programmes. Oxford: Oxford University Press; 2005.

33. World Bank, International Comparison Program database. Inflation, consumer prices (annual\%) 2013. http://data.worldbank.org/indicator/FP.CPI. TOTL.ZG/countries/1W?display=default. 
34. World Bank, International Comparison Program database. PPP conversion factor, GDP (LCU per international \$) 2013. http://data.worldbank.org/ indicator/PA.NUS.PPP.

35. UNICEF. State of the World's Children. Geneva: UNICEF; 2013.

36. Ravallion M, Chen S, Sangraula P. Dollar a day revisited. World Bank Econ Rev. 2009;23:163-84

37. Wilson N, Nghiem N, Foster R, Cobiac L, Blakely T. Estimating the cost of new public health legislation. Bull World Health Organ. 2012;90:532-9.

38. Sanghvi T. Improving the Cost-Effectiveness of Breastfeeding Promotion in Maternity Services: Summary of the USAID/LAC HNS Study in Latin America (1992-1995). San Diego, California, United States of America: Wellstart International; 1995.

39. Nersesyan M: Cost and Effective Analysis of the LINKAGES LAM Promotion Program in Jordan LINKAGES: Breastfeeding, LAM, Related Complementary Feeding, and Maternal Nutrition Program; 2005

40. Horton S. Unit Costs, Cost-effectiveness, and Financing of Nutrition Interventions. WPS 952. Washington: Population and Human Resources Dept, World Bank; 1992.

41. Pérez-Escamilla R, Curry L, Minhas D, Taylor L, Bradley E. Scaling up of breastfeeding promotion programs in low- and middle-income countries: the "breastfeeding gear" model. Adv Nutr Int Rev J. 2012;3:790-800.

42. World Health Organization (WHO). Country implementation of the International Code of Marketing of Breast-milk Substitutes Status Report 2011. Geneva, Switzerland: World Health Organization; 2012.

43. Breastfeeding Promotion Network of India (BPNI): National Consultation to Develop a Plan of Action - Resource Requirements for Enhancing Rates of Breastfeeding \& Infant and Young Child Feeding in the 12th Plan - A Report; 2011

44. Harney A. Special report: How Big Formula bought China. Reuters Business and Financial News; 2013, 7 November.

45. Lin L. China pushes breastfeeding amid medical bribe crackdown. Bloomberg. 2013;2013:30.

46. Smith J. The contribution of infant food marketing to the obesogenic environment in Australia. Breastfeed Rev. 2007;15:23-35.

47. Sobel HL, lellamo A, Raya RR, Padilla AA, Olivé J-M, Nyunt-U S. Is unimpeded marketing for breast milk substitutes responsible for the decline in breastfeeding in the Philippines? An exploratory survey and focus group analysis. Soc Sci Med. 2011;73:1445-8.

48. Horton S, Sanghvi T, Phillips M, Fiedler J, Perez-Escamilla R, Lutter C, et al. Breastfeeding promotion and priority setting in health. Health Policy Plann. 1996:11:156-68.

49. Mason J, Hunt J, Parker D, Jonsson U. Investing in Child Nutrition in Asia. Asian Dev Rev. 1999;17:1-32.

50. Oglethorpe JE. Infant feeding as a social marketing issue: a review. J Consum Policy. 1995;18:293-314.

51. Smith JP. Submission to Parliamentary Inquiry into Health Benefits of Breastfeeding; Economics of Breastfeeding, Parliamentary Inquiry into Health Benefits of Breastfeeding. Canberra: Commonwealth Parliament; 2007.

52. How to Benchmark Sales-and-Marketing Budgets http://www.inc.com/ magazine/19990201/731.html.

53. How Much Should Companies Budget for Marketing? http://frog-dog.com/ how-much-should-companies-budget-for-marketing/.

54. Sobel HL, Lellamo AD. Protecting, promoting and supporting breastfeeding mothers and children vs. the aggressive marketing of BMS: a case study. Melbourne: International Lactation Consultants Association Annual Conference Born to Breastfeed A Global Health Perspective; 2013.

55. IBFAN Asia: The World Breastfeeding Trends Initiative (WBTi), www. worldbreastfeedingtrends.org.

56. Leslie J. Women's time: a factor in the use of child survival technologies? Health Policy Plann. 1989;4:1-16.

57. Almroth S, Greiner T, Latham M. The Economic Value of Breastfeeding. New York: Cornell University Program on International Nutrition; 1979.

58. Smith JP, Ingham LH, Dunstone MD. The Economic Value of Breastfeeding in Australia, NCEPH Working Paper 40. National Centre for Epidemiology and Population Health: Australian National University, Canberra; 1998.

59. Smith JP, Forrester R. Who pays for the health benefits of exclusive breastfeeding? Analysis Mternal Time Costs. J Hum Lact. 2013;29:547-55.

60. Heymann J, Raub A, Earle A. Breastfeeding policy: a globally comparative analysis. Bull World Health Organ. 2013;91:398-406

61. Aguayo VM, Ross J, Saunero R, Torrez A, Johnston R. Monetary value of breast milk in Bolivia. Rev Panam Salud Pública. 2001;10:249-56.
62. Hatloy A, Oshaug A. Human milk: an invisible food resource. J Hum Lact. 1997;13:299-305.

63. Bartick M, Stuebe AM, Schwarz EB, Luongo C, Reinhold AG, Foster EM. Cost analysis of maternal disease associated with suboptimal breastfeeding. Obstet Gynecol. 2013;122:111-9.

64. Meier BM, Labbok M. From the bottle to the grave: Realizing a human right to breastfeeding through global health policy. Case Western Res Law Rev. 2009;60:1073.

65. IBFAN Asia: World Breastfeeding Costing Initiative (WBCi), http://ibfan.org/ upload/files/WBCi_Releases_1.1.XLSM.

\section{Submit your next manuscript to BioMed Central and take full advantage of:}

- Convenient online submission

- Thorough peer review

- No space constraints or color figure charges

- Immediate publication on acceptance

- Inclusion in PubMed, CAS, Scopus and Google Scholar

- Research which is freely available for redistribution 